\title{
Multidirectional chromosome painting between the Hirola antelope (Damaliscus hunteri, Alcelaphini, Bovidae), sheep and human
}

\author{
Raquel Chaves $^{1}$, Lutz Frö nicke ${ }^{2}$, Henrique Guedes-Pinto ${ }^{1}$ \& Johannes Wienberg ${ }^{3}$ \\ ${ }^{1}$ Department of Genetics and Biotechnology, Centre of Genetics and Biotechnology of the University of Trás- \\ os-Montes and Alto Douro-CGB/UTAD, P-5000-911 Vila Real, Portugal; Tel: p 351259350 571; Fax: p \\ 351259350 572; E-mail: rchaves@utad.pt or hgp@utad.pt; ${ }^{2}$ Current address: School of Veterinary Medicine, \\ Populations Health \& Reproduction, University of California, Davis, One Shields Avenue, CCAH Bldg./Rm. 230, \\ Davis, Ca 95616; Former Adress: Comparative Molecular Cytogenetics Section, Genetics Branch, National \\ Cancer Institute-Frederick, Frederick, MD 21702-1201, USA; ${ }^{3}$ Institute of Human Genetics, GSF-National \\ Research Center for Environment and Health and Department of Biology II, University of Munich, \\ Ingolstädter Landstr. 1, D-85758 Neuherberg, Germany;
}

*Correspondence E-mail: j.wienberg@1rz.uni-muenchen.de

Key words: chromosome evolution, chromosome painting, Damaliscus hunteri, fluorescence in-situ hybridization, paracentric inversion, Robertsonian translocations

\begin{abstract}
Chromosome specific painting probes of human, sheep and the Hirola antelope (Damaliscus hunteri) derived by flow sorting of chromosomes were used in multi directional chromosome painting experiments to better define the karyological relationship within Bovidae species (specifically, Caprini and Alcelaphini tribes) and humans. Although not all chromosomes of Damaliscus hunteri could be resolved into single peaks by flow-sorting we managed to present a complete homology map for chromosomes between the three species. When comparing the karyotype of Damaliscus hunteri with human all of the main known motives in mammalian chromosome evolution are present (i.e. associations of human homologous chromosomes 3-21, 4-8, 7-16, 14-15, 16-19 and two forms of 12-22) which were also confirmed with the sheep paint probes. Further, we observed those patterns that have been described as common derived traits for artiodactyls (i.e. associations of human homologous chromosomes 5/19 and a complex alternating pattern of hybridizations with human chromosome 14 and 15 probes). As known from classical karyotyping some of the
\end{abstract}


Damaliscus chromosomes are biarmed and were supposedly involved in Robertsonian translocations frequently found in karyotype evolution of bovids. We refined these rearrangements with the molecular probes and also delineated a chromosome painting pattern that should be the result of a paracentric inversion in the Damaliscus hunteri karyotype. This study demonstrates that multidirectional chromosome painting will be a valuable tool for the investigation of the dynamics of chromosome evolution in exotic bovid species.

\section{Introduction}

Despite great variations in chromosome numbers, chromosome evolution in Bovidae seems to have been predominantly conservative. Whereas the chromosome numbers range from $2 \mathrm{n} 1 / 430$ to $2 \mathrm{n} 1 / 460$, the number of autosomal arms (NAA) has remained almost constant at 56-58 for most species. Changes in the autosomes of the Bovidae have occurred primarily through centric fusions (Wurster \& Benirschke 1968, Effron et al. 1976, Buckland \& Evans 1978, Gallagher \& Womack 1992, Gallagher et al. 1994). Although there is good evidence of tandem rearrangements in some species (Gallagher \& Womack 1992) and simple translocations in others (Crawford et al. 1995, Vaimann et al. 1996, de Gortari et al. 1998, Frönicke \& Wienberg 2001), they seem to be the exception rather than the rule.

The genus Damaliscus (family Bovidae, subfamily Alcelaphinae) comprises three species: D. hunteri, $D$. lunatus, and D. pygargus (Kumamoto et al. 1996). Habitating in grasslands and open woodlands throughout much of subSaharan Africa, populations of Damaliscus have undergone drastic declines due to hunting, encroachment of agriculture, competition with domestic livestock, and drought (Nowak 1991, Kumamoto et al. 1996). D. hunteri is now restricted to a narrow strip between the Tana River in Kenya and the Juba River in Somalia, and is regarded as endangered (Ansell 1977, Kingdon 1982, East 1995, Kumamoto et al. 1996).

The karyotype of the Hirola antelope (Damaliscus hunteri) was first described by Kumamoto et al. (1996) with G-and C-banded karyotypes. They reported that this species has 2n 1/4 44 chromosomes in which: eight autosome pairs are metacentric/submetacentric and the remaining thirteen autosome pairs are acrocentric/telocentric. As most autosomes, the sex chromosomes are also acrocentric.

The acrocentric nature of the majority of the bovid chromosomes is a source of problems for the construction of karyotypes. In addition, banding patterns for various chromosomes are very similar. This had led to several revisions of the International System for Chromosome Nomenclature of 
Domestic Bovids [the last one date from 2000, (ISCNDB 2000)]. Comparative molecular cytogenetics studies, however, are less prone to errors since chromosomes are compared on the basis of their DNA content rather than on morphological differences. Thus, this approach has proven to be very helpful in the understanding of even complex rearrangements that occurred during the evolutionary process (Chowdhary et al. 1998, Wienberg et al. 2000, for reviews).

In general, molecular cytogenetic data show high consistency with each other. Comparative chromo- some painting maps give a complete overview about the major conserved homologous segments. Painting segments also define the boundaries of con- served homologous segments, providing a data set complementary to higher resolving but still patchy gene mapping between artiodactyls (Fr`nicke \& Schmitz et al. 1998, Wienberg 2001). Moreover, comparative chromosome painting is of extremely value for exotic species (e.g. Damaliscus hunteri), where no gene mapping data are available. The comparative painting and gene mapping data, already available for domestic bovid species (e.g. sheep, goat and cattle), will be easily transferable for these exotic species, disclosing conserved chromosome segments suitable for phylogenetic analysis.

In the present study, we established chromo- some painting probes from Damaliscus hunteri by bivariate fluorescence-activated flow sorting of chromosomes of a large part of the karyotype. We used these probes together with painting probes from human and sheep (Burkin et al. 1997) in a multidirectional paint experiment between these three species to better define the karyological relationship of the Bovidae species (specifically, Caprini and Alcelaphini tribes) and human. This report also complements previous chromosome painting results with human probes on domestic bovids [cattle (Hayes 1995, Solinas-Toldo et al. 1995, Chowdhary et al. 1996), river buialo (Ian- nuzzi et al. 1998), and sheep (Iannuzzi et al. 1999)]. Moreover, to our knowledge it represents the first chromosome painting study in an exotic species of the Bovidae.

\section{Materials and Methods}

\section{Chromosome flow sorting and generation of painting probes}

Sorting of Damaliscus hunteri chromosome was performed using a dual laser sorter (FACS Vantage; Becton Dickinson ImmunoCytometry Systems). This system allowed a bivariate analysis of the chromosomes by size and base-pair composition (Rabbits et al. 1995). About 
four hundred chromosomes were sorted from each peak in the flow karyotype. Chromosomes were sorted directly into PCR tubes containing distillated water. Painting probes of various sheep and human chromosomes was done with the same approach while others were the same as described before (Burkin et al. 1997). Chromo- some-specific probes were made by degenerate oligonucleotide primed PCR (DOP-PCR) from the flow-sorted chromosomes by using 6MW- PCR primers and amplification conditions as previously described (Rabbitts et al. 1995). The same PCR primer was also used to label the chromosome paints with digoxigenindUTP or biotin-dUTP (Roche Molecular Biochemicals) in a secondary PCR.

\section{Cell culture and chromosome preparation}

A fibroblast cell line from a single male Damaliscus hunteri (DHU) was used. The cell line was obtained from the collection held at the Laboratory of Genomic Diversity, NCI-Frederick, but was originally established at the San Diego Zoo (USA). Standard cell culture and chromosome preparation techniques for both flow sorting and cytogenetics were followed. Metaphase preparations from sheep [Ovis aries (OAR), "Churra da Terra Quente" breed] were prepared from peripheral blood using standard protocols (Chaves et al.
2002). In various cases G-banding before in situ hybridization was as performed that followed a previously published protocol (Wienberg et al. 1992).

\section{Fluorescent in situ hybridization and} image processing

In situ hybridization of painting probes to Damaliscus hunteri and sheep metaphase spreads was as previously described (Wienberg et al. 1997). Briefly, $15 \mathrm{ml}$ of the hybridization mixture $(50 \%$ formamide, 2 SSC, $10 \%$ dextran sulfate, $500 \mathrm{ng}$ of painting probe, $5 \mathrm{mg}$ of sonicated Damaliscus genomic DNA, $5 \mathrm{mg}$ of sonicated sheep genomic DNA or $5 \mathrm{mg}$ human cot-1 DNA, respectively, and $10 \mathrm{mg}$ of salmon sperm DNA) were denatured at $70 \mathrm{C}$ for $10 \mathrm{~min}$, allowed to preanneal $90 \mathrm{~min}$ at $37^{\circ} \mathrm{C}$, dropped on denatured chromosome preparations, and mounted with $22 \times 22 \mathrm{~mm}$ cover slips. Slides were denatured in $70 \%$ formamide, $2 \times \mathrm{SSC}$ at $70^{\circ} \mathrm{C}$ for $1 \mathrm{~min}$. In-situ hybridization was performed for $72 \mathrm{~h}$ at $37^{\circ} \mathrm{C}$. Detection of the hybridization signal was as published (Pinkel et al. 1986, Wienberg et al. 1997). After hybridization and washing of the slides, digoxigenin-labeled chromosome paints were detected with rhodamine- labelled goat-anti-digoxigenin antibodies (Roche Molecular Biochemicals), and biotin-labelled probes were detected with Avidin-FITC (Vector Laboratories).

Digital images were obtained with a 
cooled CCD camera (Photometrics Quantix series) coupled to a Zeiss Axioplan II microscope. The DAPI, rhodamine, and FITC images were acquired and merged by using Smart-Capture VP software (DigitalScientific, Cambridge, UK). To facilitate chromosome identification, computer- enhanced 4'-6-diamidino-2phenylindole (DAPI) banding was used concurrently with in-situ hybridization. Chromosome numbering for sheep and Damaliscus followed the standardization of the Domestic Bovid karyotypes (ISCNDB 2000).

In Figure 2, DAPI staining was presented in red to optimize differentiation in printing, and consequently rhodamine (red) was presented in white; contrast and color optimization functions were used and all afected the whole of the image equally.

\section{Results}

\section{Damaliscus hunteri flow karyotype}

The bivariate flow karyotype of Damaliscus hunteri was resolved in 17 peaks. Flow sorting and DOP-PCR provided chromosome paints from each peak. These paints were then hybridized to Damaliscus hunteri metaphases to identify the chromosome content of each peak of the flow karyotype. Individual paints were obtained for chromosomes $2,3,6,8,9,10,14,16$,
17, $\mathrm{X}$ and $\mathrm{Y}$, (see Figure 1). Six peaks contained multiple chromosomes. When processing the DNA from the sorted chromosomes all peaks provided paints of exceptionally good quality.

\section{Reciprocal chromosome painting between Damaliscus hunteri and Ovis aries}

Paints of individual chromosomes from Damaliscus hunteri were hybridized to sheep meta- phases (Figure 2a-b). The reciprocal chromosome painting was also performed by hybridizing paints of all sheep chromosomes onto Damaliscus hunteri metaphases (Figure 2c-d). The reciprocal chromosome painting between Damaliscus and sheep gave consistent results in both directions. Damaliscus chromosome specific paints derived from chromosomes 9, 10, 14, $16,17, \mathrm{X}$ and $\mathrm{Y}$ hybridized to a single sheep homologue each (OAR8, OAR13, OAR18,
OAR20,
OAR23,
OARX, OARY;

see Figure 3). All other individual paints that were derived from the biarmed chromosomes showed hybridization signals on two sheep homologs each (OAR2q/OAR24,
OAR1p/OAR11,
OAR6/
OAR12,

OAR7/OAR10; see Figure 3 and Table 1).

In the reverse painting the complete set of sheep paints on Damaliscus metaphases gave a total of 31 distinct signals (Figure 3). No reciprocal translocation was 
observed that would distinguish the karyotype of these two species. Fifteen Damaliscus chromosomes (9-21, X and Y) were entirely delineated by sheep chromosome paints. The remaining eight chromosomes from Damaliscus (the biarmed ones) were painted by two sheep paints. Chromosomes OAR1/OAR14, OAR2/OAR24, OAR1/OAR11, OAR4/OAR5, OAR3/OAR9, OAR6/OAR12, and OAR2/OAR3 painted Damaliscus chromosomes from 1 to 8 , respectively (Figure 3).

Table 1. A listing of Damaliscus hunteri chromosomes (DHU) and their homologues in cattle (BTA) and sheep (OAR). The first description of the karyotype Damaliscus hunteri followed the ISCNDA (1989) nomenclature (Kumamoto et al. 1996). We present the chromosome homologies following ISCNDB (2000) nomenclature.

\begin{tabular}{|c|c|c|}
\hline \multicolumn{3}{|c|}{ Present Work ISCNDB (2000) } \\
\hline DHU Chrs & BTA Chrs & OAR Chrs \\
\hline 1 & $1: 18$ & $1 \mathrm{q} ; 14$ \\
\hline 2 & $2: 25$ & $2 q ; 24$ \\
\hline 3 & $3: 19$ & $1 \mathrm{p} ; 11$ \\
\hline 4 & 4.7 & $4 ; 5$ \\
\hline 5 & $5: 14$ & $3 \mathrm{q}: 9$ \\
\hline 6 & $6: 16$ & $6 ; 12$ \\
\hline 7 & $8: 11$ & $2 p ; 3 p$ \\
\hline 8 & $10 ; 12$ & $7 ; 10$ \\
\hline 9 & 9 & 8 \\
\hline 10 & 13 & 13 \\
\hline 11 & 15 & 15 \\
\hline 12 & 17 & 17 \\
\hline 13 & 20 & 16 \\
\hline 14 & 21 & 18 \\
\hline 15 & 22 & 19 \\
\hline 16 & 23 & 20 \\
\hline 17 & 24 & 23 \\
\hline 18 & 26 & 22 \\
\hline 19 & 27 & 26 \\
\hline 20 & 28 & 25 \\
\hline 21 & 29 & 21 \\
\hline $\mathrm{x}$ & $\mathrm{x}$ & $\mathrm{x}$ \\
\hline $\mathrm{Y}$ & $\mathrm{Y}$. & $\mathrm{Y}$ \\
\hline
\end{tabular}

\section{Human chromosome paints on} Damaliscus hunteri metaphase

Paints specific to each human chromosome, except the Y, were used to paint Damaliscus metaphases (Figure $2 \mathrm{e}-\mathrm{h}$ ). The 23 human paints (autosomes and $\mathrm{X}$ ) delineated a total of 51 con- served segments on Damaliscus chromosomes (Figure 3). Only on two Damaliscus chromosomes a hybridization pattern was observed that did not correspond to the reported patterns in the cattle homolog (Hayes 1995). The human paint probe 12 delineated two segments on DHU12 (HSA12/HSA4/HSA12/HSA22, see Figure $2 \mathrm{~g}$ magenta arrow and Figure 3). In Damaliscus chromosome $5 \mathrm{q}$ a less complex hybridization pattern was observed compared to cattle with the human chromosome 22 probe (Figure 3 ).

\section{Discussion}

This is the first report of a multidirectional chromosome painting with an exotic Bovidae species - Damaliscus hunteri. The chromosomes of this species were flowsorted and paints were generated. The hybridization of Damaliscus paints to sheep chromosomes and the reverse hybridization of human and sheep probes to Damaliscus chromosomes revealed a 
closely complete homology map between the three species. The experiments confirm the high conservation of the general genome organization between the two bovids. The main differences between the sheep and Damaliscus karyotype are several independent centric fusions of different ancestral chromosomes in both lineages. No reciprocal translocation was observed that would distinguish both karyotypes.

The reciprocal painting confirmed previous description of homologies obtained with Gbanding (Kumamoto et al. 1996) which conclude that the Damaliscus hunteri karyotype has evolved by fusions of ancestral acrocentric chromosomes. There were, however, several problems comparing the numbering of chromosomes involved in the rearrangements. These problems are due to the very similar banding pattern of some chromosomes within the bovid karyotype. Recently, this lead to several revisions in nomenclature for all domestic bovids. Thus, it w a s difficult to re- evaluate the chromosome numbering used in the first description of the G-banded karyotype of Damaliscus hunteri. The chromosome numbering in the present chromosome painting experiments follows the International System for Chromosome Nomenclature of Domestic Bovids (ISCND 2000). The nomenclature is now well defined by gene mapping, cytogenetics, and also by molecular probes such as human chromosome specicc paints. Table 1 presents the homologies observed between Damaliscus hunteri and other bovids. In summary, as proposed by the 'centric fusion' theory (Wurster \& Benirschke 1968, Effron et al. 1976, Buckland \& Evans 1978, Gallagher \&Womack 1992, Gallagher et al. 1994), the Damaliscus hunteri karyotype evolved through eight translocations that were specified in the present experiments as chromosomes homologous to cattle $1 ; 18$, $2 ; 25,3 ; 19,4 ; 7,5 ; 14,6 ; 16,8 ; 11$ and $10 ; 12$. Paints specific to each human chromosome delineated 51 conserved segments (see Figure 3) for the comparative map between these two species which is very close to the numbers observed for other bovids that are 48-52 in cattle (Hayes 1995, Solinas-Toldo et al. 1995, Chowdhary et al. 1996), 48 in sheep (Iannuzzi et al. 1998) and 50 in the river buffalo (Iannuzzi et al. 1999). When comparing the karyotypes of Damaliscus hunteri and humans all of the main motives known in mammalian chromosome evolution are present (i.e. associations of human homologous chromosomes 3/21, 4/8, 7/16, 14/15, 16/19 and two forms of 12/22). Further, we observed those patterns that have been described as common derived traits for artiodactyls (i.e. associations of human homologous chromosomes 5/19 and a complex alternating pat- tern of hybridizations with human chromosome 14 and 15 probes) (Figure 3) (Wienberg et al. 
2002). However, when comparing the Damaliscus karyotype with the assumed ancestral form for bovids as found in cattle two minor additional intrachromosomal rearrangements were observed with the human chromosome painting probes. The missing of an additional signal with the human chromo- some 22 probe on Damaliscus chromosome $5 \mathrm{q}$ points to an inversion in the phylogeny leading to cattle. On the other hand, Damaliscus chromosome 12 had an additional signal with the human chromosome 12 probe not found in the homolog of other Bovidae. This signal would point to a paracentric inversion that should have occurred in the Alcelaphini tribe after the splitting of the phylogeny leading to other bovids. From the present experiment, however, we cannot conclude whether this rearrangement is specific to Damaliscus hunteri or is a landmark rearrangement for the entire Alcelaphini tribe.

Finally, linkage mapping analysis (de Gortari et al. 1998) and comparative FISHmapping with specific markers (Iannuzzi et al. 2001) demonstrated a translocation of a small pericentromeric region that differentiated bovine and caprine chromosomes 9 and 14 (homologous to OAR8 and OAR9, respectively). Frönicke \& Wienberg (2001) confirmed this same chromosome rearrangement with sheep paint probes. Taken this into account, and as our results suggest that the Damaliscus chromosomes $5 p$ and 9 are entire homologous to sheep chromosomes 9 and 8 respectively, HSA6 signals could be expected in the pericentromeric region of DHU5p. Our experiments did not delineate this specific segment of HSA6 probably because the physical mapping between species of different orders (Damaliscus and human) provides a lower resolution when compared to linkage mapping analysis or com- parative FISH-mapping with probes derived from different orders. Similarly, Iannnuzzi et al. (1999) also did not report such a HSA6 segment when hybridizing human paint probes to sheep chromosomes.

Further experiments using both the painting probes presented here and comparative FISH- mapping with locus specific probes such us BAC clones along chromosomes will offer the opportunity to achieve a more detailed understanding of the dynamics of bovid chromosome evolution

\section{Acknowledgements}

This work was supported by the project POCTI/ BIA/11285/98 of the Science and Technology Foundation from Portugal. We would like to thank Gary Stone (NCI-Frederick, Frederick, USA) for the flow sorting of chromosomes and Roscoe 
Stanyon (NCI-Frederick) for the culture of Damaliscus hunteri cells and many suggestions. We thank M. A. FergusonSmith and D. Burkin (Cambridge University, Cambridge, UK) for the sheep chromosome painting probes.

\section{References}

Ansell WFH (1977) Order Artiodactyla. Part 15. In: Meester J, Setzer HW, eds. The Mammals of Africa. An identification Manual. Washington DC: Smithsonian Institution Press, pp 1-84.

Buckland RA, Evans HJ(1978) Cytogenetic aspects of phylogeny in the Bovidae I. Gbanding. Cytogenet Cell Genet 21: 4263.

Burkin DJ, O’Brien PCM, Broad TE et al. (1997) Isolation of chromosome-specific paints from high-resolution flow karyotypes of the sheep (Ovis aries). Chromosome Res 5: 102-108.

Chaves R, Adega F, Santos S, Heslop-Harrison JS, Guedes- Pinto H (2002) In situ hybridization and chromosome banding in mammalian species. Cytogenet Genome Res 96: 113-116.

Chowdhary BP, Fronicke L, Gustavsson I, Scherthan H (1996) Comparative analysis of the cattle and human genomes, detection of ZOOFISH and gene mapping-based chro- mosomal homologies. Mamm Genome 7: 297-302.

Chowdhary BP, Raudsepp T, Frö nicke L, Scherthan H (1998) Emerging patterns of comparative genome organization in some mammalian species as revealed by Zoo-FISH. Genome Res 8: 77-589.

Crawford AM, Dodds KG, Ede AJ et al. (1995) An autosomal genetic linkage map of the sheep genome. Genetics 140:
$703-724$.

de Gortari MJ, Freking BA, Cuthbertson RP et al. (1998) A second-generation linkage map of the sheep genome. Mamm Genome 9: 204-209.

East R (1995) Antelope survey update. Number 1. IUCN/SSC Antelope Specialist Group Report. Gland, Switzerland: International Union for Conservation of Nature and Natural Resources.

Effron M, Bogart MH, Kumamoto AT, Benirschke K (1976) Chromosome studies in the mammalian subfamily Antilo- pinae. Genetica 46: 419-444.

Frönicke L, Wienberg J(2001) Comparative chromosome painting defines the high rate of karyotype changes between pigs and bovids. Mamm Genome 12: 442-449.

Gallagher DS, Womack JE (1992) Chromosome conservation in the Bovidae. J Hered 82: $287-$ 298.

Gallagher DS, Derr JN, Womack JE (1994) Chromosome

conservation among the advanced pecorans and determi- nation of the primitive bovid karyotype.

J Hered 85: 204-

210.

Hayes H (1995) Chromosome painting with human chro- mosome-specific DNA libraries reveals the extent and distribution of conserved segments in bovine chromosomes. Cytogenet Cell Genet 71: 168-174.

Iannuzzi L, Di MeoGP, Perucatti A, Bardaro T (1998) ZOO-FISH and R-banding reveal extensive conservation of human chromosome regions in euchromatic regions of river buffalo chromosomes. Cytogenet Cell Genet 82: 210-214.

Iannuzzi L, Di Meo GP, Perucatti A, Incarnato D (1999) Comparison of the human with the sheep genomes by use of human chromosome-specific painting probes. 
Mamm Genome 10: 719-723.

Iannuzzi L, Di Meo GP, Perucatti A, Schibler L, Incarnato D, Cribiu EP (2001) Comparative FISH-mapping in river buffalo and sheep chromosomes: assignment of forty autosomal type I loci from sixteen human chromosomes. Cytogenet Cell Genet 94: 43-48.

ISCNDA (1989) International System for Cytogenetic

Nomenclature of Domestic Animals. In: Di Berardino D, Hayes H, Fries R, Long S, eds. Cytogenet Cell Genet 53: 65-79.

ISCNDB (2000) International System for Chromosome Nomenclature of Domestic. In: Bovids, Di Berardino D, Di Meo GP, Gallagher DS, Hayes H, Iannuzzi L, eds. Cytogenet Cell Genet 92: 283-299 (2001).

Kingdon J(1982) East African Mammals; An Atlas of Evolution in Africa, Vol. IIID (Bovids). Chicago: University of Chicago Press .

Kumamoto AT, Charter SJ, Houck ML, Frahm M (1996) Chromosomes of Damaliscus (Artiodactyla, Bovidae): simple and complex centric fusion rearrangements. Chromosome Res 4: 614-621.

Nowak RM (1991) Walker's Mammals of the World, 5th edn., Vol. II. Baltimore: Johns Hopkins University Press.

Pinkel D, Straume T, Gray JH (1986) Cytogenetic analysis using quantitative, highsensitivity, fluorescence hybridiza- tion. Proc Natl Acad Sci USA 86: 2934-2938.

Rabbits P, Impey H, Heppell-Parton A et al. (1995) Chro- mosome specific paints from a high resolution flow karyotype of the mouse. Nat Genet 9: 369-375.

Schmitz A, Oustry A, Vaiman D, Chaput B, Frelat G, Cribiu EP (1998) Comparative karyotype of pig and cattle using whole chromosome painting probes. Hereditas 128: 257-263.

Solinas-Toldo S, Lengauer C, Fries R (1995)
Comparative genome map of human and cattle. Genomics 27: 489-496. Vaiman D, Schibler L, Bourgeois F, Oustry A, Amigues Y, Cribiu EP (1996) A genetic linkage map of the male goat genome. Genetics 144: 279-305.

Wienberg J, Stanyon R, Jauch A, Cremer T (1992) Homologies in human and Macaca fuscata chromosomes revealed by in situ suppression hybridization with human chromosome specific DNA libraries. Chromosoma 101: 265-270.

Wienberg J, Stanyon R, Nash WG et al. (1997) Conservation of human vs. feline genome organisation revealed by reciprocal chromosome painting. Cytogenet Cell Genet 77: 211-217.

Wienberg J, Frönicke L, Stanyon R (2000) Insights into mammalian genome organization and evolution b y molecular cytogenetics. In: Clark MS, ed. Comparative Genomics. Dordrecht, Netherlands: Kluwer Academic Publishers, p p 207-244.

Wurster DH, Benirschke K (1968) Chromosome studies in the superfamily Bovidae. Chromosoma 25: $152-171$. 


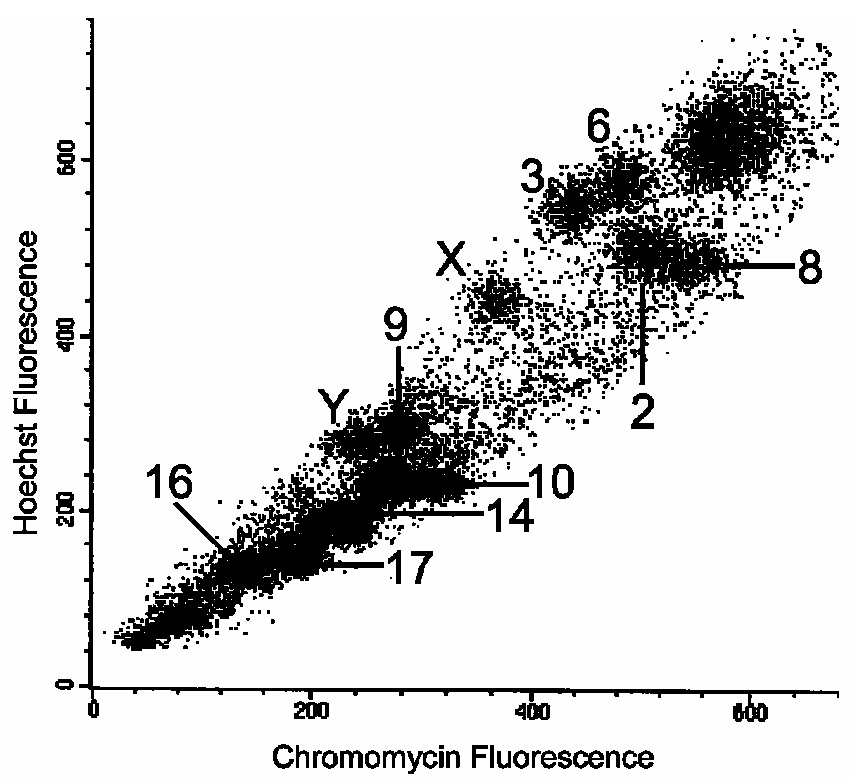

Figure 1. The bivariate flow karyotype of the Damaliscus hunteri is shown. Chromosomes were sorted for DNA content and AT to GC base pair ratios into 17 peaks after staining with Hoechst (vertical axis) and chromomycin-A3 (horizontal axis). The numbers in the figure indicate 11 Damaliscus chromosomes for which highly pure sorts of individual chromosomes were obtained. 

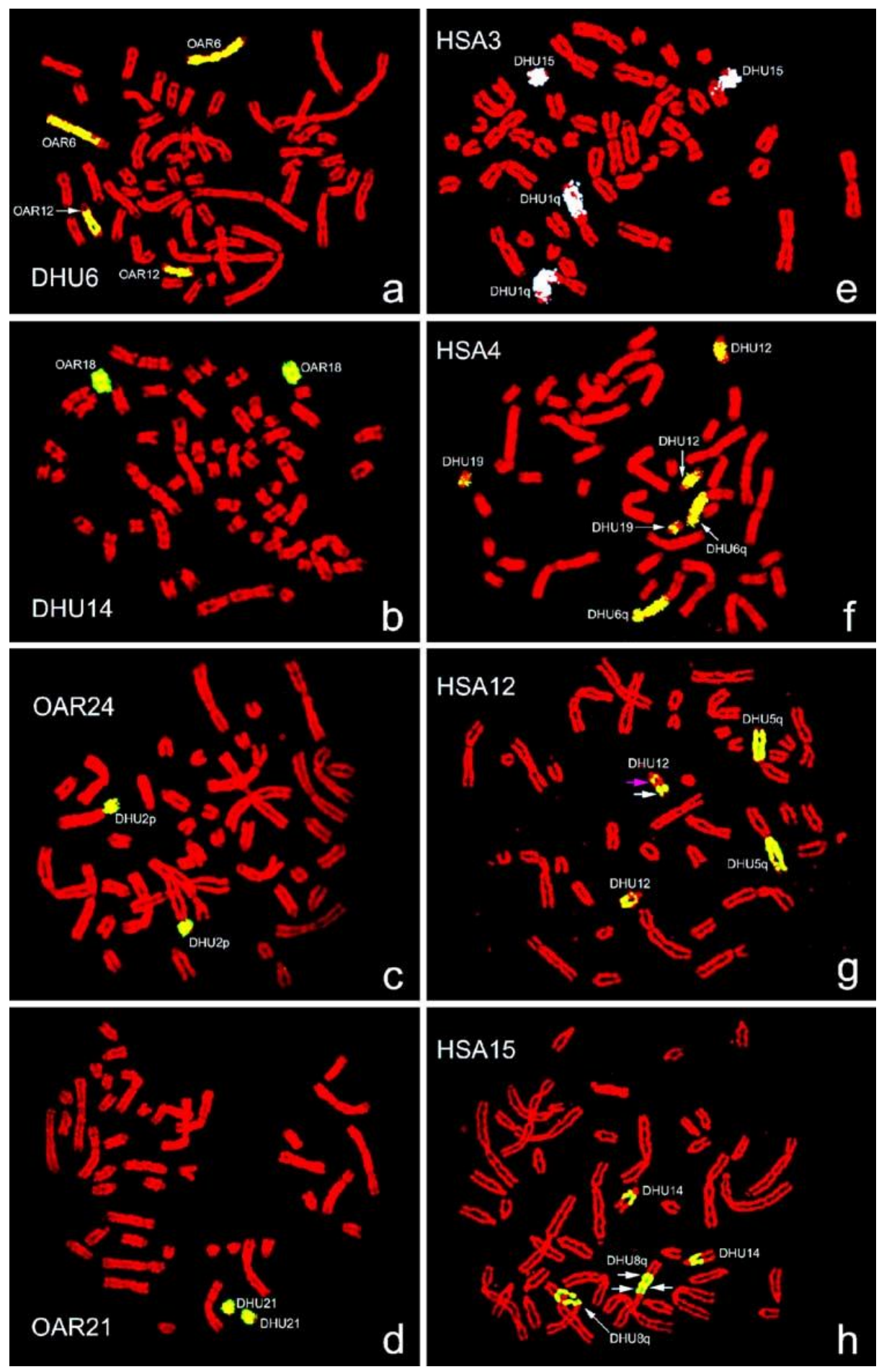

Figure 2. Representative FISH signals of comparative chromosome painting experiments on sheep (a-b) and Damaliscus hunteri (DHU) metaphases (c-h). The paint probes used are indicated in the corner of each picture segment. The target chromosomes are numbered close to the hybridization signals. (a-b) Hybridization of DHU chromosome-specific painting probes to sheep chromosomes. (c-d) Sheep paint probes on DHU chromosomes. (e-h) Human paint probes on DHU chromosomes; human paint probe HSA12 delineates a segment on DHU chromosome 12 that has not yet been described in bovid homologs (magenta arrow). 


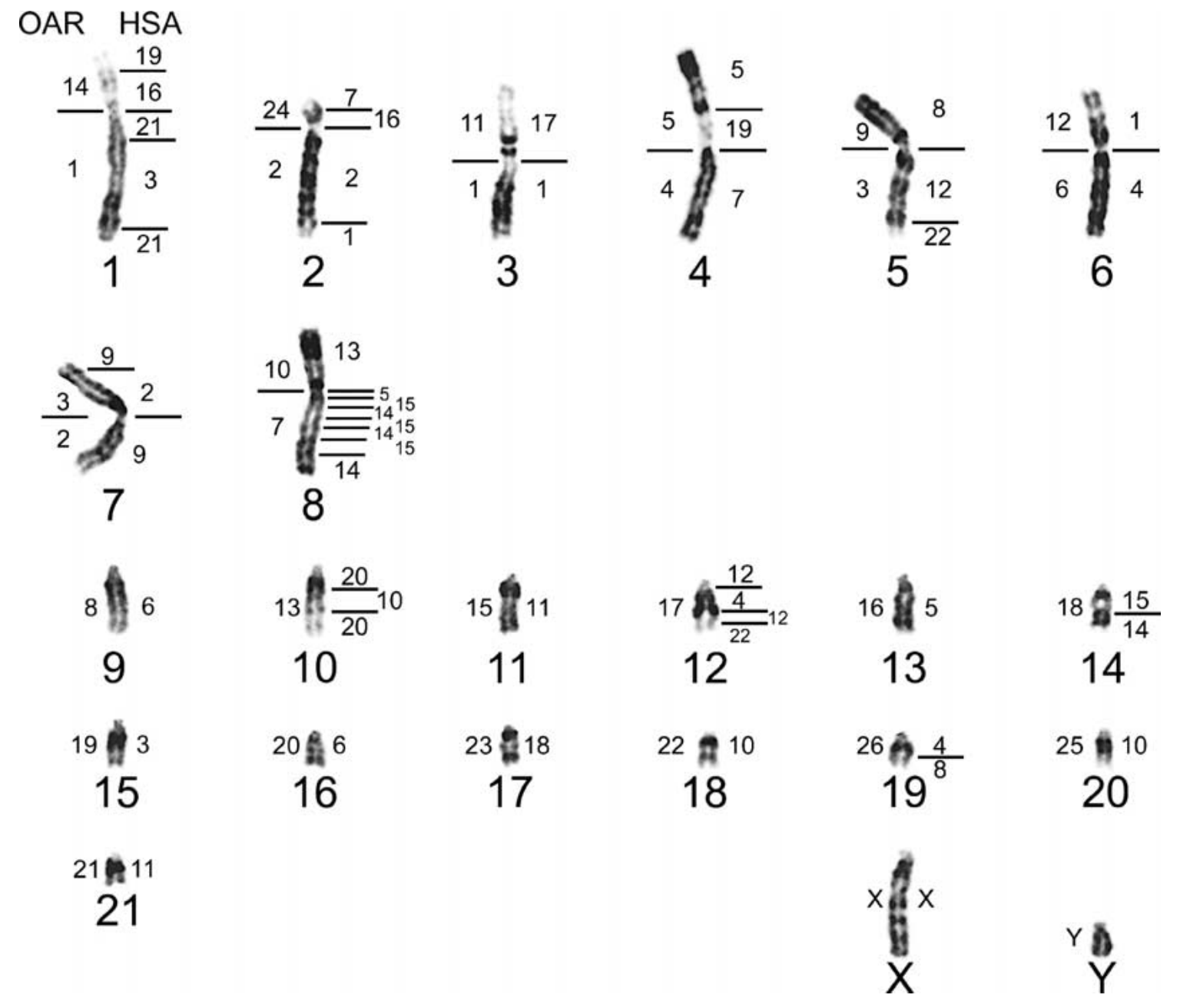

Figure 3. The G-banded karyotype of a male Damaliscus hunteri. The chromosomes a r e numbered below. Homologies to sheep chromosomes are shown to the left, and to with human chromosomes are shown to the right of each Damaliscus chromosome 